\title{
Grãos de oleaginosas na alimentação de novilhos zebuínos: consumo, digestibilidade e desempenho ${ }^{1}$
}

\section{Marcelo Silva Bassi ${ }^{2}$, Márcio Machado Ladeira ${ }^{2 *}$, Mário Luiz Chizzotti2 ${ }^{*}$, Fernanda Helena Martins Chizzotti ${ }^{2}$, Dalton Mendes de Oliveira ${ }^{2}$, Otávio Rodrigues Machado Neto $^{2}$, José Rodolfo Reis de Carvalho², Álvaro Augusto Nogueira Neto ${ }^{2}$}

\author{
1 Financiado pela Fapemig. \\ 2 Departamento de Zootecnia, Universidade Federal de Lavras, Lavras, MG, 37200-000. \\ * Pesquisador do CNPq e INCT-Ciência Animal.
}

RESUMO - Avaliaram-se o consumo, o desempenho e a digestibilidade de dietas contendo diferentes grãos de oleaginosas

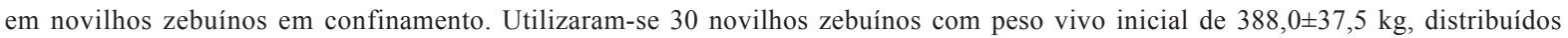
em delineamento inteiramente casualizado. As dietas foram formuladas com silagem de milho e quatro concentrados: um sem suplementação de lipídeos e três com a inclusão de grão de soja, caroço de algodão ou semente de linhaça. As rações, isonitrogenadas, apresentaram relação concentrado:volumoso 60:40 e foram fornecidas à vontade. Para determinação da digestibilidade aparente total, a produção fecal foi estimada utilizando-se fibra em detergente neutro indigestivel como indicador interno. O menor consumo de matéria seca $(7,20 \mathrm{~kg} / \mathrm{dia})$ foi observado para a dieta contendo caroço de algodão, mas, entre as outras dietas, não houve diferenças nesta variável. O ganho médio diário foi menor quando se utilizou a dieta contendo caroço de algodão em relação à dieta sem lipídeo (0,93 vs. 1,16 kg/dia, respectivamente). No entanto, não houve diferença no ganho médio diário destas dietas em relação às demais. Houve redução da digestiblidade da fibra em detergente neutro na dieta contendo semente de linhaça. Adicionalmente, houve redução na digestibilidade dos carboidratos não-fibrosos nas dietas contendo caroço de algodão e semente de linhaça em relação à dieta com grão de soja, a qual não diferiu da dieta controle. A inclusão de caroço de algodão moído em dietas para bovinos em confinamento deve ser feita com cautela, pois pode provocar redução no consumo de matéria seca e no ganho médio diário. No entanto, a eficiência alimentar não é afetada pela adição de oleaginosas na dieta de bovinos de corte quando o nível máximo de extrato etéreo na matéria seca total da dieta não excede $6 \%$.

Palavras-chave: confinamento, extrato etéreo, lipídeos

\section{Oilseeds in zebu cattle diet: intake, digestibility and performance}

\begin{abstract}
This study was conducted to evaluate feed intake, performance and of digestibility diet containing different oilseeds to beef cattle finished in feedlot. Thirty zebu steers $(388.0 \pm 37.5 \mathrm{~kg}$ of body weight) were used in a completed randomized design. The diets consisted of corn silage and four different concentrates: one without lipids and three with inclusion of soybeans, cottonseed and linseed. The diets, which were isonitrogenous, had roughage:concentrate ratio of 60:40 and were offered ad libitum. To determinate the total apparent digestibility of nutrients, the fecal output was estimated through internal marker indigestible neutral detergent fiber. The lowest dry matter intake was observed for cottonseed (7.20 kg/d), but among the other diets, the dry matter intake did not differ. The average daily gain was lower when cottonseed was used, in comparison with linseed ( 0.93 vs. $1.16 \mathrm{~kg} / \mathrm{d}$, respectively). However, there was no difference on average daily gain in relation to other diets. There was reduction in the digestibility of neutral detergent fiber in linseed diet. Additionally, there was a reduction in the neutral detergent fiber digestibility in diets with cottonseed and linseed compared with soybeans, which did not differ from the control diet. The inclusion of ground cottonseed in feedlot beef cattle diets should be realized with caution, since it can decrease dry matter intake and average daily gain. However, feed efficiency is not affected by the addition of oilseeds in beef cattle diets when the maximum ether extract level in total dry matter diet does not exceed $6 \%$.
\end{abstract}

Key Words: ether extract, feedlot, lipids

\section{Introdução}

O consumo de alimentos e seus nutrientes é o fator mais importante na determinação do desempenho animal e pode ser influenciado pelas características do animal, do alimento e das condições de alimentação (Van Soest, 1994). Segundo o NRC (1996), existe alta correlação entre o consumo de matéria seca e a concentração energética da dieta, visto que, dietas com baixa digestibilidade e menos energia limitam o consumo por enchimento do rúmen e diminuem a taxa de 
passagem, enquanto o consumo de dietas ricas em energia e de alta digestibilidade regulam a ingestão por atendimento das exigências energéticas do animal e por fatores metabólicos.

A utilização de lipídeos na alimentação de ruminantes cresceu de forma acentuada nas últimas décadas, pois houve maior conhecimento sobre o uso das fontes que contêm estes nutrientes (Zinn \& Jorquera, 2007). Em dietas onde a energia se torna limitante e a quantidade máxima de grãos tem que ser respeitada para que se evite distúrbios fermentativos como a acidose. Portanto, a adição de lipídeos se torna alternativa para a nutrição de animais confinados, pois promove aumento da densidade energética dessas dietas. Além disso, os lipídeos são utilizados em rações por aumentarem a capacidade de absorção de vitaminas lipossolúveis, fornecerem ácidos graxos essenciais e atuarem como precursores de diferentes metabólitos.

Segundo Jenkins et al. (2008), a utilização de ácidos graxos pelas bactérias ruminais é restrita. $\mathrm{O}$ excesso de ácidos graxos insaturados e triglicerídeos pode causar alteração na fermentação ruminal, devido à supressão das atividades de bactérias celulolíticas e metanogênicas, geralmente gram-positivas. Além disso, o uso de elevadas quantidades de lipídeos na dieta de ruminantes pode prejudicar o consumo, podendo causar queda na digestibilidade e aproveitamento dos nutrientes (Palmquist, 1991; Jenkins, 1993).

A bibliografia comprova que os resultados sobre o uso de fontes de lipídeos sobre a digestibilidade são diversos. Jorge et al. (2008) observaram que a utilização do caroço de algodão não afetou a digestibilidade da matéria seca e da fibra da dieta. Todavia, Oliveira et al. (2007) utilizaram lipídeos na forma de grãos e óleo de soja e notaram que o óleo de soja influenciou negativamente na digestibilidade da fibra. Portanto, além do nível de extrato etéreo, a fonte pode influenciar a digestibilidade e o desempenho animal.

Objetivou-se avaliar o consumo e a digestibilidade aparente total de nutrientes e o desempenho de novilhos zebuínos alimentados com dietas contendo diferentes grãos de oleaginosas.

\section{Material e Métodos}

$\mathrm{O}$ experimento foi conduzido nas dependências do Departamento de Zootecnia da Universidade Federal de Lavras no período de agosto a novembro de 2008.

Foram utilizados 30 novilhos zebuínos, com idade inicial média de 23 meses e peso vivo inicial médio de $388,0 \pm 37,5 \mathrm{~kg}$. Os novilhos foram confinados em baias individuais cobertas, com área de $2 \mathrm{~m}^{2}$ por animal, piso de concreto com camas de areia, comedouros individuais e bebedouros automáticos comuns a duas baias.

O período experimental teve duração de 84 dias e foi precedido de um período de adaptação de 28 dias, no qual os animais receberam a mesma dieta experimental. No início do período de adaptação, os animais foram tratados contra ecto e endoparasitos (Ivomec Gold, Merial). Os animais foram pesados no início e final do período experimental, após jejum de 16 horas.

As dietas foram compostas de silagem de milho como volumoso e quatro concentrados contendo grãos de oleaginosas moídos, totalizando quatro dietas experimentais: uma sem lipídeo adicional e três contendo grão de soja, caroço de algodão ou semente de linhaça (Tabelas 1 e 2).

Tabela 1 - Composição percentual de ingredientes e química das dietas experimentais

\begin{tabular}{|c|c|c|c|c|}
\hline \multirow[t]{2}{*}{ Ingrediente } & \multicolumn{4}{|c|}{ Composição (\%MS) } \\
\hline & Sem lipídeos & Grão de soja & Caroço de algodão & Semente de linhaça \\
\hline Silagem de milho & 40,0 & 40,0 & 40,0 & 40,0 \\
\hline Farelo de soja & 9,0 & - & 3,0 & 7,8 \\
\hline Soja grão & - & 14,4 & - & - \\
\hline Caroço de algodão & - & - & 18,0 & - \\
\hline \multicolumn{5}{|l|}{ Nutrientes } \\
\hline Matéria seca, \% MN & 64,2 & 64,7 & 64,7 & 64,4 \\
\hline Proteína bruta, \% MS & 13,2 & 13,3 & 13,3 & 13,4 \\
\hline Fibra em detergente neutro, $\% \mathrm{MS}$ & 32,3 & 31,2 & 38,4 & 33,1 \\
\hline Fibra em detergente ácido, \% MS & 20,8 & 20,7 & 27,2 & 23,1 \\
\hline Carboidratos não fibrosos, \% MS & 46,0 & 44,3 & 37,0 & 43,7 \\
\hline
\end{tabular}

MN - matéria natural; MS - matéria seca.

${ }^{1}$ Níveis de garantia por quilograma do produto: cálcio - $235 \mathrm{~g}$; fósforo - $45 \mathrm{~g}$; enxofre - $23 \mathrm{~g}$; sódio - $80,18 \mathrm{~g}$; zinco - $2,38 \mathrm{mg}$; cobre - $625 \mathrm{mg}$; ferro - $1,18 \mathrm{mg}$; manganês - $312 \mathrm{mg}$ : cobalto - $32 \mathrm{mg}$; iodo - 41,6 mg; selênio - 11,25 mg; vit. A - 70.000 UI; vit. D3 - 5.000 UI; vit. E - 15 UI; niacina - 3,33 mg. 
Tabela 2 - Composição química dos ingredientes das dietas

\begin{tabular}{|c|c|c|c|c|c|c|}
\hline Item & $\begin{array}{l}\text { Silagem } \\
\text { de milho }\end{array}$ & $\begin{array}{l}\text { Farelo } \\
\text { de soja }\end{array}$ & $\begin{array}{l}\text { Milho } \\
\text { moído }\end{array}$ & $\begin{array}{c}\text { Grão } \\
\text { de soja }\end{array}$ & $\begin{array}{l}\text { Caroço de } \\
\text { algodão }\end{array}$ & $\begin{array}{l}\text { Grão de } \\
\text { linhaça }\end{array}$ \\
\hline Matéria seca, \% MN & 25,9 & 89,8 & 88,5 & 91,4 & 90,2 & 93,5 \\
\hline Matéria orgânica, \% MS & 94,2 & 93,5 & 98,4 & 94,9 & 94,9 & 96,5 \\
\hline Proteína bruta, \% MS & 8,6 & 52,0 & 9,9 & 39,4 & 20,8 & 23,0 \\
\hline NIDN, \% NT & 18,9 & 4,5 & 14,4 & 18,7 & 7,0 & 8,7 \\
\hline NIDA, \% NT & 13,3 & 6,4 & 9,1 & 6,4 & 4,0 & 5,6 \\
\hline Carboidratos não fibrosos, \% MS & 25,8 & 23,9 & 71,0 & 14,7 & 9,6 & 8,7 \\
\hline Fibra detergente ácido, \% MS & 38,2 & 10,0 & 5,2 & 21,5 & 36,2 & 34,7 \\
\hline Lignina & 4,5 & 2,2 & 1,2 & 3,8 & 6,7 & 7,6 \\
\hline
\end{tabular}

As rações foram formuladas para ser isonitrogenadas, segundo o NRC (2000), e foram fornecidas ad libitum aos animais às $7 \mathrm{~h} 30 \mathrm{~min}$ e às $15 \mathrm{~h} 30 \mathrm{~min}$. As oleaginosas foram moídas em peneira de malha de $5 \mathrm{~mm}$ com a finalidade de aumentar a disponibilidade ruminal dos lipídeos.

A quantidade de ração fornecida foi ajustada diariamente para permitir sobras equivalentes a $5 \%$ do total fornecido. Foram anotadas as quantidades de ração fornecida e das sobras para se obter o consumo diário de matéria seca. As amostras dos ingredientes dos concentrados e da silagem foram coletadas a cada 14 dias e originaram amostras compostas que, depois de submetidas a pré-secagem em estufa de ventilação forçada a $65^{\circ} \mathrm{C}$ por 72 horas, foram moídas em moinho com peneira de malha de $1 \mathrm{~mm}$. As determinações de matéria seca (MS), matéria orgânica(MO), proteína bruta $(\mathrm{PB})$, extrato etéreo (EE), fibra em detergente neutro (FDN) e em detergente ácido (FDA) foram realizadas conforme metodologias descritas por Silva \& Queiroz (2002). Os carboidratos não-fibrosos (CNF) foram obtidos segundo Sniffen et al. (1992).

Para determinação da digestibilidade aparente total da matéria seca e dos nutrientes, estimou-se a produção de matéria seca fecal pela concentração do indicador interno fibra em detergente neutro indigestível (FDNi). As fezes foram coletadas nos dias 67, 68, 69 e 81, 82 e 83 do período experimental, conforme proposto por Ladeira et al. (1999). Ao final do período de coleta, foi composta uma amostra por animal com base no peso seco ao ar. As amostras de fezes foram pré-secas em estufa com ventilação forcada a $60^{\circ} \mathrm{C}$, por 72 horas, e processadas em moinho de facas com peneiras de porosidade $2 \mathrm{~mm}$.

Para avaliação da FDNi, as amostras de fezes e alimentos foram acondicionadas em sacos de tecido não-tecido (TNT$100 \mathrm{~g} / \mathrm{m}^{2}$ ), com dimensões de $4 \times 5 \mathrm{~cm}$, segundo a relação de $20 \mathrm{mg}$ de matéria seca por centímetro quadrado de superfície (Nocek, 1988). Antes da incubação das amostras, duas vacas da raça Holandesa providas de fístulas ruminais foram alimentadas com as dietas experimentais durante sete dias. Posteriormente ao período de adaptação dos animais, as amostras de fezes e alimentos foram incubadas no rúmen por 264 horas, segundo adaptação de técnica descrita por Casali et al. (2008). Após a retirada do rúmen, os sacos foram lavados em água corrente e colocadas em lavadora semiautomática por três tempos de 15 minutos, trocando-se a água a cada período. Imediatamente após esse processo, os sacos foram secos em estufa de ventilação forçada a $60^{\circ} \mathrm{C}$ por 72 horas e avaliados em aparelho analisador de fibra.

O teor de nutrientes digestíveis totais (NDT) foi obtido a partir da equação: $\mathrm{NDT}=\mathrm{PBD}+2,25 \times \mathrm{EED}+\mathrm{FDNcpD}+$ CNFD, em que PBD, EED, FDNcpD e CNFD significam, respectivamente, proteína bruta digestível, extrato etéreo digestível, fibra em detergente neutro (isenta de cinzas e proteína) digestível e carboidratos não-fibrosos digestíveis.

O delineamento utilizado foi o inteiramente casualizado com quatro tratamentos. Os dados obtidos foram submetidos à análise de variância utilizando-se o procedimento GLM do SAS (Statistical Analysis System, versão 9.1) e as médias comparadas pelo teste Tukey a $5 \%$ de probabilidade.

\section{Resultados e Discussão}

O diâmetro geométrico médio obtido foi de $823,446 \mathrm{e}$ $849 \mu \mathrm{m}$ para o grão de soja, o caroço de algodão e a semente de linhaça, respectivamente, segundo metodologia descrita por Zanotto \& Bellaver (1996). Esse resultado sugere que a dieta contendo caroço de algodão aumentou a disponibilidade ruminal de lipídeos, uma vez que apresentou o menor diâmetro geométrico médio.

Os animais alimentados com a dieta sem lipídeo adicional apresentaram o maior consumo de MS, em kg/dia, enquanto aqueles que receberam a dieta com caroço de algodão, o menor consumo de MS (Tabela 3). Esse fato pode estar 
Tabela 3 - Consumo de nutrientes em novilhos zebuínos alimentados com dietas sem lipídeo, grão de soja, caroço de algodão e semente de linhaça

\begin{tabular}{|c|c|c|c|c|c|c|}
\hline \multirow[b]{2}{*}{ Item } & \multicolumn{4}{|c|}{ Dieta } & \multirow[b]{2}{*}{ EPM } & \multirow[b]{2}{*}{$\mathrm{P}$} \\
\hline & Sem lipídeo & Grão de soja & Caroço de algodão & Semente de linhaça & & \\
\hline Número de animais & 7 & 7 & 8 & 8 & - & - \\
\hline Matéria seca $(\% \mathrm{PV})$ & $1,79 \mathrm{a}$ & $1,71 \mathrm{ab}$ & $1,55 \mathrm{c}$ & $1,76 \mathrm{ab}$ & 0,05 & 0,032 \\
\hline Matéria orgânica (kg/dia) & $7,17 \mathrm{a}$ & $6,93 b$ & $6,09 \mathrm{c}$ & $7,04 \mathrm{~b}$ & 0,27 & 0,040 \\
\hline Proteína bruta (kg/dia) & $1,18 \mathrm{a}$ & $1,12 \mathrm{a}$ & $0,96 b$ & $1,11 \mathrm{a}$ & 0,04 & $<0,001$ \\
\hline Fibra em detergente neutro $(\% \mathrm{PV})$ & 0,60 & 0,53 & 0,60 & 0,59 & 0,02 & 0,062 \\
\hline Carboidratos não-fibrosos (kg/dia) & $3,92 \mathrm{a}$ & $3,65 \mathrm{a}$ & $2,68 \mathrm{~b}$ & $3,51 \mathrm{a}$ & 0,15 & $<0,001$ \\
\hline
\end{tabular}

Média seguidas de mesma letra nas linhas não diferem $(\mathrm{P}<0,05)$ pelo teste Tukey a $5 \%$ de probabilidade; EPM - erro-padrão da média.

relacionado ao maior teor de FDN do caroço de algodão em relação às demais oleaginosas utilizadas (Tabela 2). Outro fator que pode ter contribuído para o menor consumo destas dietas foi o menor diâmetro geométrico médio do caroço de algodão moído em comparação às demais fontes de lipídeos. Esta característica provavelmente ocasionou maior liberação de lipídeos, os quais podem ter afetado negativamente o consumo. As fontes de lipídeos grão de soja e semente de linhaça promoveram consumo de MS semelhante à dieta sem fonte acidional de lipídeos quando esta variável foi expressa em porcentagem do peso vivo.

Geralmente duas teorias explicam os principais efeitos inibitórios dos lipídeos sobre a fermentação ruminal e o consumo. Uma está relacionada ao impedimento físico que os lipídeos exercem sobre os microrganismos, por meio de um camada hidrofóbica, que impede o metabolismo e a perfeita aderência das bactérias à fibra, afetando desta forma a proximidade das enzimas fibrolíticas ao material fibroso. A outra teoria tem sido atribuída aos efeitos tóxicos dos ácidos graxos insaturados sobre os microrganismos. Neste caso, há alteração na fluidez da membrana citoplasmática, afetando a permeabilidade desta (Jenkins, 1993; Harfoot \& Hazlewood, 1997).

De forma geral, o consumo de MS observado para todas as dietas foi baixo (Tabela 3), visto que animais zebuínos com peso corporal semelhante aos animais deste estudo e com ganho médio de $1,0 \mathrm{~kg} /$ dia geralmente apresentam consumo de MS superior a 2\% do PV. Um provável estresse devido ao confinamento ter ocorrido em baias individuais é a principal explicação para esse comportamento. Segundo Valadares Filho et al. (2006), o manejo alimentar em baias individuais pode ser prejudicial aos resultados experimentais voltados às variáveis de consumo e desempenho animal, em função do estresse causado pelo manejo de contenção, além do comprometimento do padrão natural de consumo em grupo, uma vez que os bovinos são influenciados por padrões sociais de comportamento. Ainda segundo esses autores, animais zebuínos apresentam maior dificuldade de adaptação a este tipo de manejo. Ribeiro (2010), em experimento com novilhos zebuínos não-castrados terminados em confinamento de baias coletivas, utilizou uma dieta sem lipídeo adicional igual à deste estudo e verificou maior consumo de MS para estes animais $(9,76 \mathrm{~kg} / \mathrm{dia})$.

Consumo de MS semelhante $(8,18 \mathrm{~kg} / \mathrm{dia})$ ao deste experimento foi observado por Fiorentini (2009) em trabalho realizado com novilhas recebendo uma dieta com $40 \%$ de concentrado à base de grão de soja, $60 \%$ de silagem de milho e $5,8 \%$ de EE. Enquanto o consumo de MS das dietas contendo caroço de algodão foi menor, o consumo de $\mathrm{MO}$, $\mathrm{PB}$ e CNF, consequentemente, também foram inferiores. $\mathrm{O}$ consumo de FDN (kg/dia) foi semelhante entre as dietas, apesar do menor consumo de MS observado para a dieta contendo caroço de algodão. Isto ocorreu devido ao maior teor de FDN presente no caroço de algodão (Tabela 2). Além disso, não houve efeito das fontes de lipídeos sobre o consumo de FDN, expresso em porcentagem do peso vivo, cujo valor médio de $0,58 \%$ PV. De acordo com Mertens (1987), quando o consumo é limitado por fatores físicos, o consumo de FDN mantém-se próximo ao valor de 1,2\% do peso vivo. Dessa forma, pode-se inferir que provavelmente houve regulação energética do consumo de matéria seca nas condições deste experimento.

O consumo de nutrientes digestíveis totais (NDT), com exceção da dieta contendo caroço de algodão, foi semelhante entre a dieta sem suplementação de lipídeos e as demais com inclusão de fontes de lipídeos $(5,41 \mathrm{~kg}$ vs 5,45; 4,62; 4,95 kg para as dietas sem lipídeos adicionais, com grão de soja, caroço de algodão e semente de linhaça, respectivamente), o que provavelmente ocorreu devido ao aumento da densidade energética da ração.

O menor GMD foi observado nos bovinos alimentados com a dieta contendo caroço de algodão (Tabela 4). Esse fato provavelmente ocorreu devido aos menores consumos de MS, MO e PB observados para esta dieta em comparação 
às demais. Consequentemente, o consumo de energia também foi inferior para esta dieta em relação às demais.

Apesar do menor GMD dos animais alimentados com caroço de algodão, verifca-se que a eficiência alimentar não foi influenciada pelas dietas, o que ocorreu devido ao menor consumo de MS. Todavia, deve-se ter cautela na utilização desta dieta quando se desejam elevados ganhos de peso, pois a limitação do consumo pode inviabilizar altas taxas de crescimento.

A eficiência alimentar observada foi semelhante à relatada por Aferri et al. (2005), que observaram valores de 0,124 e 0,131 em dietas com 5\% de sais de cálcio de ácidos graxos e $21 \%$ de caroço de algodão, respectivamente. Conclui-se, portanto, que apesar do baixo consumo de MS encontrado no experimento, os valores de eficiência alimentar foram compatíveis com o manejo alimentar e os animais utilizados.

Jorge et al. (2008) avaliaram o consumo e o desempenho de novilhos submetidos a dietas contendo ou não caroço de algodão e observam redução no consumo de MS da dieta com este ingrediente, embora o GMD e a conversão alimentar não tenham sido afetados. De acordo com Zinn \& Jorquera (2007), bovinos adaptados à suplementação lipídica podem tolerar até $7 \%$ de gordura suplementar, sem alterações no desempenho, desde que a adaptação dos mesmos à dieta seja feita de forma adequada.

Não houve efeito das diferentes fontes de lipídeos sobre a digestibilidade da MS, MO, PB e EE (Tabela 5).
Entretanto, a digestibilidade da FDN foi menor para as dietas contendo semente de linhaça. $\mathrm{O}$ fato de a semente de linhaça ser rica em ácido linolênico pode ter afetado negativamente a microbiota ruminal, visto que, quanto maior o grau de insaturação do ácido graxo, maior será o efeito tóxico.

Em trabalho realizado por Wada et al. (2008), foram relatados menores valores na digestibilidade de MS nos animais recebendo dietas contendo linhaça. Embora esses autores não tenham encontrado diferença estatística na digestibilidade da fibra, citaram que a mesma foi numericamente inferior e atribuíram isso aos lipídeos contidos na semente de linhaça, os quais podem ter provocado inibição dos microrganismos celulolíticos.

A suplementação com lipídeos não reduziu a digestibilidade da FDN nas dietas suplementadas com grão de soja e caroço de algodão. Segundo Nagaraja et al. (1997), geralmente os ácidos graxos insaturados são tóxicos para as bactérias gram-positivas cujo mecanismo pode envolver uma alteração na permeabilidade da membrana celular, que reduz a capacidade da célula regular o $\mathrm{pH}$ intracelular e a captação de nutrientes. Ainda segundo estes autores os ácidos oleico, linoleico e linolênico inibem o crescimento das bactérias celuloliticas B. fibrisolvens, R. albus e $R$. flavefaciens.

Segundo Leite (2006), tem-se observado redução na digestibilidade da fibra quando fontes lipídicas são adicionadas às rações. A magnitude de redução está

Tabela 4 - Peso vivo inicial, ganho médio diário e conversão alimentar de novilhos zebuínos alimentados com dietas sem lipídeo adicional, grão de soja, caroço de algodão e semente de linhaça

\begin{tabular}{|c|c|c|c|c|c|c|}
\hline \multirow[b]{2}{*}{ Item } & \multicolumn{4}{|c|}{ Dieta } & \multirow[t]{2}{*}{ EPM } & \multirow[t]{2}{*}{$P$} \\
\hline & Sem lipídeo & Grão de soja & Caroço de algodão & Semente de linhaça & & \\
\hline $\mathrm{n}$ & 7 & 7 & 8 & 8 & - & - \\
\hline Peso vivo inicial, $\mathrm{kg}$ & 373 & 377 & 361 & 360 & 11,1 & 0,604 \\
\hline Ganho médio diário, $\mathrm{kg}$ & $1,16 \mathrm{a}$ & $1,10 \mathrm{a}$ & $0,93 b$ & $0,99 \mathrm{a}$ & 0,05 & 0,030 \\
\hline Eficiência alimentar & 0,136 & 0,137 & 0,130 & 0,119 & 0,01 & 0,491 \\
\hline
\end{tabular}

Médias seguidas de letras iguais nas linhas não diferem entre si pelo teste Tukey a 5\% de probabilidade; EPM - erro-padrão da média.

Tabela 5 - Coeficientes de digestibilidade aparentes totais dos nutrientes e teores de nutrientes digestíveis totais obtidos de novilhos zebuínos alimentados com dietas sem lipídeo, grão de soja, caroço de algodão e semente de linhaça

\begin{tabular}{|c|c|c|c|c|c|c|}
\hline \multirow[b]{2}{*}{ Item } & \multicolumn{4}{|c|}{ Dieta } & \multirow[b]{2}{*}{ EPM } & \multirow[b]{2}{*}{$\mathrm{P}$} \\
\hline & Sem lipídeo & Grão de soja & Caroço de algodão & Semente de linhaça & & \\
\hline Matéria seca $(\%)$ & 60,1 & 64,0 & 61,4 & 56,7 & 0,02 & 0,094 \\
\hline Matéria orgânica (\%) & 58,7 & 54,6 & 53,4 & 52,5 & 0,02 & 0,110 \\
\hline Proteína bruta (\%) & 64,6 & 65,9 & 65,8 & 64,0 & 0,02 & 0,872 \\
\hline Extrato etéreo $(\%)$ & 73,1 & 68,0 & 71,8 & 68,2 & 0,02 & 0,412 \\
\hline Fibra em detergente neutro $(\%)$ & $47,3 \mathrm{a}$ & $48,9 \mathrm{a}$ & $54,5 \mathrm{a}$ & $43,5 b$ & 0,03 & 0,050 \\
\hline Carboidratos não-fibrosos (\%) & $66,8 \mathrm{ab}$ & $73,2 \mathrm{a}$ & $63,9 b$ & $63,2 b$ & 0,01 & $<0,001$ \\
\hline Nutrientes digestíveis totais (\%) & 62,2 & 66,6 & 64,1 & 59,9 & 0,02 & 0,093 \\
\hline
\end{tabular}

Médias seguidas de mesma letra na mesma linha não diferem $(\mathrm{P}>0,05)$ pelo teste Tukey a $5 \%$ de probabilidade; EPM - erro-padrão da média. 
relacionada não só à quantidade, mas também ao tipo de ácido graxo presente no suplemento, uma vez que lipídeos ricos em ácidos graxos insaturados tendem a provocar maior redução na digestibilidade.

Outro fator a se considerar é a forma de utilização da fonte lipídica, na qual os óleos apresentam grande disponibilidade à hidrólise e, consequentemente, apresentam maior toxicidade em comparação às oleaginosas inteiras. Neste estudo, a moagem aumentou a disponibilidade dos ácidos graxos, mas provavelmente não chegou a liberá-los em quantidades semelhantes àquelas em que se utilizam os óleos.

Em relação à digestibilidade dos carboidratos nãofibrosos, não foi verificado ( $\mathrm{P}>0,05)$ efeito da suplementação da soja grão sobre a digestibilidade deste nutriente em comparação à dieta sem lipídeo adicional. As dietas contendo caroço de algodão e semente de linhaça promoveram redução da digestibilidade dos carboidratos não-fibrosos quando comparadas à soja grão.

Não houve efeito das fontes de lipídeos sobre a porcentagem de NDT das dietas (Tabela5), provavelmente em virtude do aumento da densidade energética das mesmas.

\section{Conclusões}

A inclusão de caroço de algodão moído em dietas para bovinos em confinamento deve ser feita com cautela, pois reduz o consumo de matéria seca e, consequentemente, o desempenho animal. O uso deste ingrediente na dieta reduz a digestibilade aparente total da FDN. A digestiblidade da FDN é prejudicada quando a dieta contém semente de linhaça. O grão de soja e a semente de linhaça moídos na dieta de bovinos em confinamento promovem desempenho animal semelhante a dietas sem lipídeo adicional quando o nível máximo de extrato etéreo na matéria seca total da dieta não excede $6 \%$.

\section{Referências}

AFERRI, G.; LEME, P.R.; SILVA, S.L. et al. Desempenho e características da carcaça de novilhos alimentados com dietas contendo diferentes fontes de gordura. Revista Brasileira de Zootecnia, v.34, n.5, p.1651-1658, 2005

ALLEN, M.S. Effects of diet on short-term regulation of feed intake by lactating dairy cattle. Journal of Dairy Science, v. 83, n.7, p.1598-1630, 2000.

CASALI, A.O.; DETMANN, E.; VALADARES FILHO, S.C. et al. Influência do tempo de incubação e do tamanho de partículas sobre os teores de compostos indigestíveis em alimentos e fezes bovinas obtidos por procedimentos in situ. Revista Brasileira de Zootecnia, v.37, p.335-342, 2008.

FIORENTINI, G. Fontes lipídicas na terminação de novilhas. 2009. 73f. Dissertação (Mestrado em Zootecnia) - Universidade Estadual Paulista, Jaboticabal.
HARFOOT, C.G.; HAZLEWOOD, G.P. Lipid metabolism in the rumen. In: HOBSON, P.N.; STWART, C.S. (Eds.). The rumen microbial ecosystem. Glasgow: Blackie Academic \& Professional, 1997. p.382-426.

JENKINS, T.C. Lipid metabolism in the rumen. Journal of Dairy Science, v.76, n.12, p.3851-63, 1993.

JENKINS, T.C.; WALLACE, R.J.; MOATE, P.J. et al. Recent advances in biohydrogenation of unsaturated fatty acids within the rumen microbial ecosystem. Journal of Animal Science, v.86, p.397-412, 2008

JORGE, J.R.V.; ZEOULA, L.M.; PRADO, I.N. et al. Gordura protegida sobre o desempenho, carcaça e composição química da carne de novilhos holandês. Archivos de Zootecnia, v.58, n.223, p.371-382, 2009

JORGE, J.R.V.; ZEOULA, L.M.; PRADO, I.N. et al. Lipídios em dietas para novilhos holandeses: digestibilidade aparente. Revista Brasileira de Saúde e Produção Animal, v.9, p.743-753, 2008.

LADEIRA, M.M.; VALADARES FILHO, S.C.; COELHO DA SILVA, J.F. et al. Consumo e digestibilidade aparentes totais e parciais de dietas contendo diferentes níveis de concentrados em novilhos nelore. Revista Brasileira de Zootecnia, v.28, n.2, p.395-403, 1999.

LEITE, L.C. Perfil dos ácidos graxos do leite e metabolismo de lipídios no rúmen de vacas recebendo dietas com alto ou baixo teor de concentrado e óleo de soja ou de peixe. 2006. 97f. Tese (Doutorado em Ciência Animal e Pastagens) Escola Superior de Agricultura Luiz de Queiroz, Piracicaba.

MERTENS, D.R. Predicting intake and digestibility using mathematical models of ruminal function. Journal of Animal Science, v.64, n.5, p.1548-1558, 1987.

MOLETTA, J.L. Utilização de soja grão ou caroço de algodão na terminação de bovinos de corte em confinamento. In: REUNIÃO ANUAL DA SOCIEDADE BRASILEIRA DE ZOOTECNIA, 36., 1999, Porto Alegre. Anais... São Paulo: Gnosis, 1999. (CD-ROM).

NAGARAJA, T.G.; NEWBOLD, C.J.; VAN NEVEL, C.J. et al. Manipulation of ruminal fermentation. In: HOBSON, P.N.; STWART, C.S. The rumen microbial ecosystem. Glasgow: Blackie Academic \& Professional, 1997. p.523-632.

NATIONAL RESEARCH COUNCIL - NRC. Nutrient requirements of beef cattle. 7.ed. Washington, D.C.: National Academy, 1996. 242p.

NATIONAL RESEARCH COUNCIL - NRC. Nutrients requeriments of beef cattle. 7.ed. Washington, D.C., 2000. 244p.

NELSON, M.L.; BUSBOOM, J.R.; ROSS, C.F.V. et al. Effects of supplemental fat on growth performance and quality of beef from steers fed corn finishing diets. Journal of Animal Science, v.6, p.936-948, 2008.

NOCEK, J.E. In situ and other methods to estimate ruminal protein and energy digestibility. A review. Journal of Dairy Science, v.71, p.2051-2069, 1988.

PALMQUIST, D.L. Influence of source and amount of dietary fat on digestibility in lactating cows. Journal of Dairy Science, v.74, p.1354-1360, 1991.

OLIVEIRA, R.L.; ASSUNÇÃO, D.M.P.; BARBOSA, M.A.A.F. et al Efeito do fornecimento de diferentes fontes de lipídeos na dieta sobre o consumo, a digestibilidade e o $\mathrm{N}$-uréico plasmático de novilhos bubalinos em confinamento. Revista Brasileira de Zootecnia, v.36, p.733-738, 2007.

RIBEIRO, J.S. Eficiência de produção, características de carcaça e qualidade da carne de animais zebuínos confinados. 2010. 101f. Tese (Doutorado em Zootecnia) - Universidade Federal de Lavras, Lavras.

SILVA, D.J.; QUEIROZ, A.C. Análises de alimentos (métodos químicos e biológicos). 3.ed. Viçosa, MG: Editora UFV, 2002. $235 \mathrm{p}$. 
SNIFFEN, C.J.; O'CONNOR, J.D.; VAN SOEST, P.J. et al. A net carbohydrate and protein system for evaluating cattle diets in carbohydrate and protein availability. Journal of Animal Science, v.70, n.12, p.3562-3577, 1992.

VALADARES FILHO, S.C.; MORAES, E.H.B.K; DETMANN, E. Perspectivas do uso de indicadores para estimar o consumo individual de bovinos alimentados em grupo. In: REUNIÃO ANUAL DA SOCIEDADE BRASILEIRA DE ZOOTECNIA, 43., 2006, João Pessoa. Anais... João Pessoa: SBZ, 2006. 31 p.

VAN SOEST, P.J. Nutritional ecology of the ruminant. 2.ed. Ithaca: Cornell University Press, 1994. 476p.
WADA, Y.F.; PRADO, N.I.; SILVA, R.R. et al. Grãos de linhaça e de canola sobre o desempenho, digestibilidade aparente e características de carcaça de novilhas nelore terminadas em confinamento. Ciência Animal Brasileira, v.9, n4, p.883-895, 2008.

ZINN, R.A.; JORQUERA, A.P. Feed value of supplemental fats used in feedlot cattle diets. Veterinary Clinics Food Animal, v.23, p.247-268, 2007.

ZANOTTO, L.D.; BELLAVER, C. Método de determinação da granulometria de ingredientes para o uso em rações de suínos e aves. (S.1.): Centro Nacional de Pesquisa de Suínos e Aves/EMBRAPA, 1996. p.1-5. (Comunicado técnico, 215). 